\title{
Making Amines Strong Bases: Thermodynamic Stabilization of Protonated Guests in a Highly-Charged Supramolecular Host
}

\author{
Michael D. Pluth, Robert G. Bergman,* and Kenneth N. Raymond* \\ Contribution from the Department of Chemistry, University of California, Berkeley, California, \\ 94720-1460, USA
}

Corresponding Authors: Prof. Robert G. Bergman, Prof. Kenneth N. Raymond, Department of Chemistry, University of California, Berkeley, CA 94720-1460 (USA). Fax: (+1) 510-642-7714 (Bergman). Fax: (+1) 510-486-5283 (Raymond). E-mail: rbergman@berkeley.edu, raymond@socrates.berkeley.edu

Abstract A highly-charged, cavity-containing supramolecular assembly formed by metal-ligand interactions acts as a host to dramatically shift the effective basicity of encapsulated protonated amine guests. The scope of encapsulated protonated amine and phosphine guests shows size selectivity consistent with a constrained binding environment. Protonation of the encapsulated guests is confirmed by ${ }^{31} \mathrm{P}$ NMR studies, mass spectrometry studies, and the $\mathrm{pH}$ dependence of guest encapsulation. Rates of guest self-exchange were measured using the Selective Inversion Recovery method and were found to correlate with the size rather than the basicity of the guests. The activation parameters for guest self-exchange are consistent with the established mechanism for guest exchange. The binding constants of the protonated amines are then used to calculate the effective basicity of the encapsulated amines. Depending on the nature of the guest, shifts in the effective basicities of the encapsulated amines of up to $4.5 \mathrm{p} K_{\mathrm{a}}$ units are observed, signifying a substantial stabilization of the protonated form of the guest molecule and effectively making phosphines and amines strong bases.
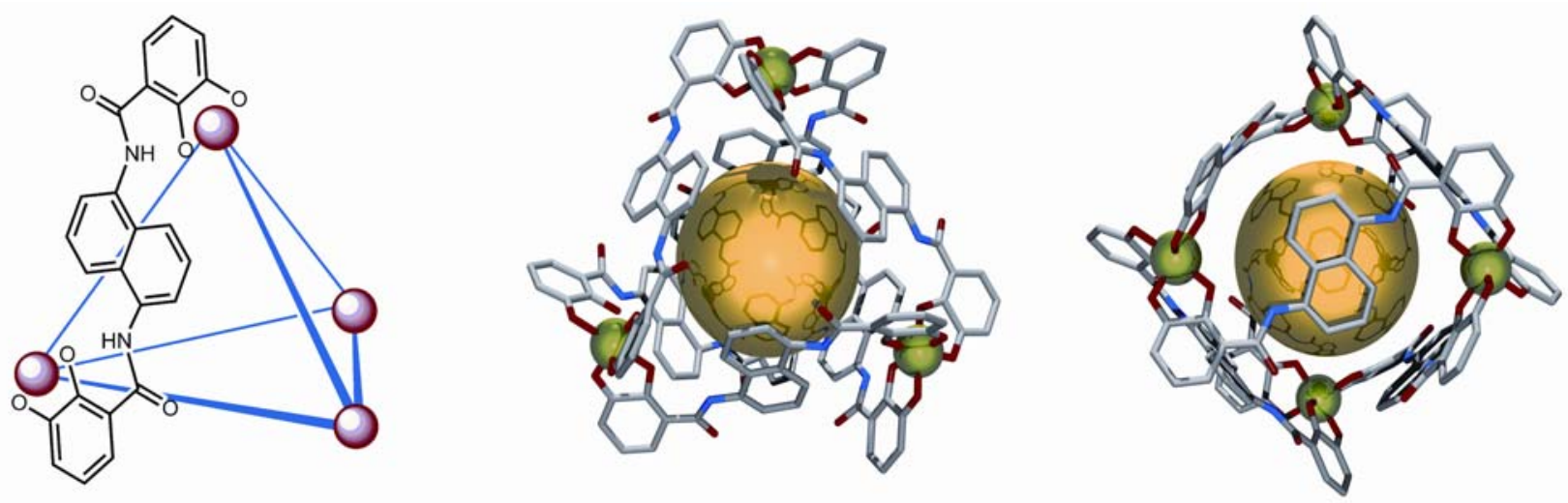

Figure 1. Left: A schematic representation of 1 with one ligand is shown for clarity. Middle: A model of 1 with a generic spherical guest viewed opposite the aperture on the three-fold axis through which guests exchange. Right: A model of $\mathbf{1}$ with a generic spherical guest viewed down the two-fold axis. 


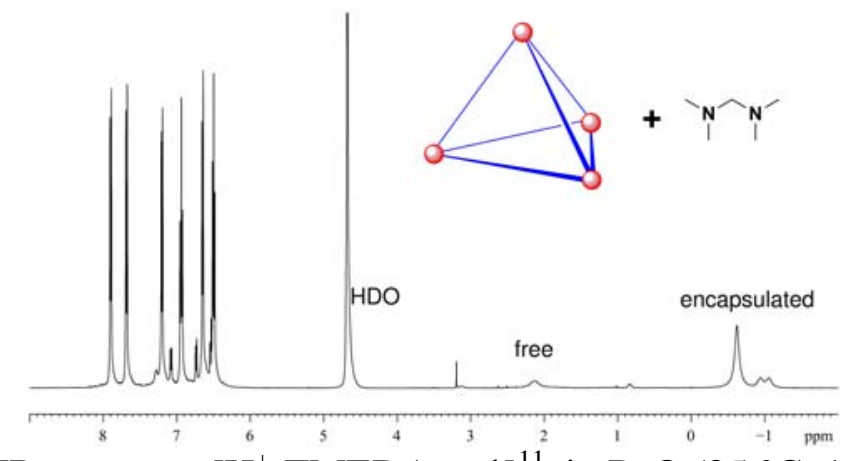

Figure 2. ${ }^{1} \mathrm{H}$ NMR spectrum $\left[\mathrm{H}^{+}-\mathrm{TMEDA} \subset \mathbf{1}\right]^{11-}$ in $\mathrm{D}_{2} \mathrm{O}\left(25^{\circ} \mathrm{C}, 11 \mathrm{mM}, 500 \mathrm{MHz}\right)$.

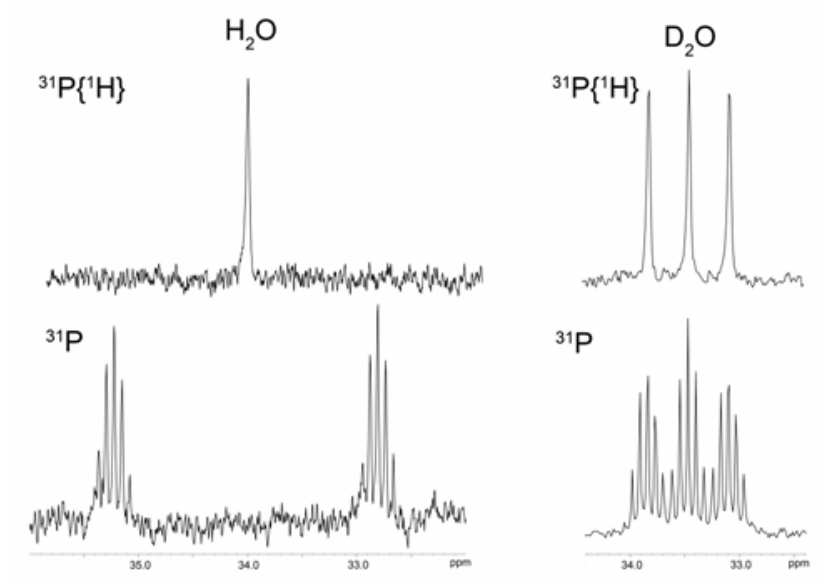

Figure 3. Left: ${ }^{31} \mathrm{P}\left\{{ }^{1} \mathrm{H}\right\}$ (top) and ${ }^{31} \mathrm{P}$ (bottom) NMR spectra of $\left[\mathrm{H}^{+}-\mathrm{DMPM} \subset \mathbf{1}\right]^{11-}$ in $\mathrm{H}_{2} \mathrm{O}$. Right: ${ }^{31} \mathrm{P}\left\{{ }^{1} \mathrm{H}\right\}$ (top) and ${ }^{31} \mathrm{P}$ (bottom) NMR spectra of $\left[\mathrm{H}^{+}-\mathrm{DMPM} \subset \mathbf{1}\right]^{11-}$ in $\mathrm{D}_{2} \mathrm{O}$. 

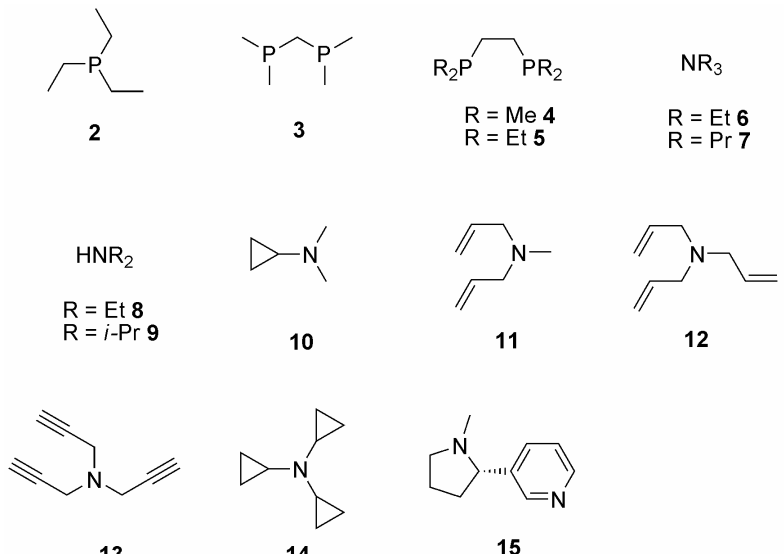

13

14

15
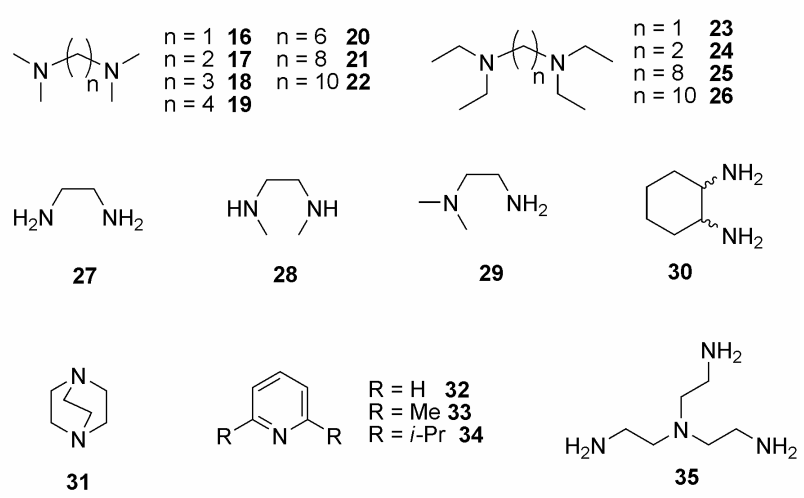

Figure 4. The scope of amines and phosphines screened as guests in $\mathbf{1 .}$

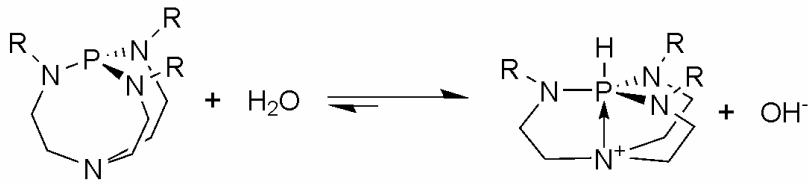

$$
\begin{array}{ll}
\mathrm{R}=\mathrm{H} & 36 \\
\mathrm{R}=\mathrm{Me} & 37
\end{array}
$$

Figure 5. Schematic showing the protonation of the pro-azaphosphatranes. 

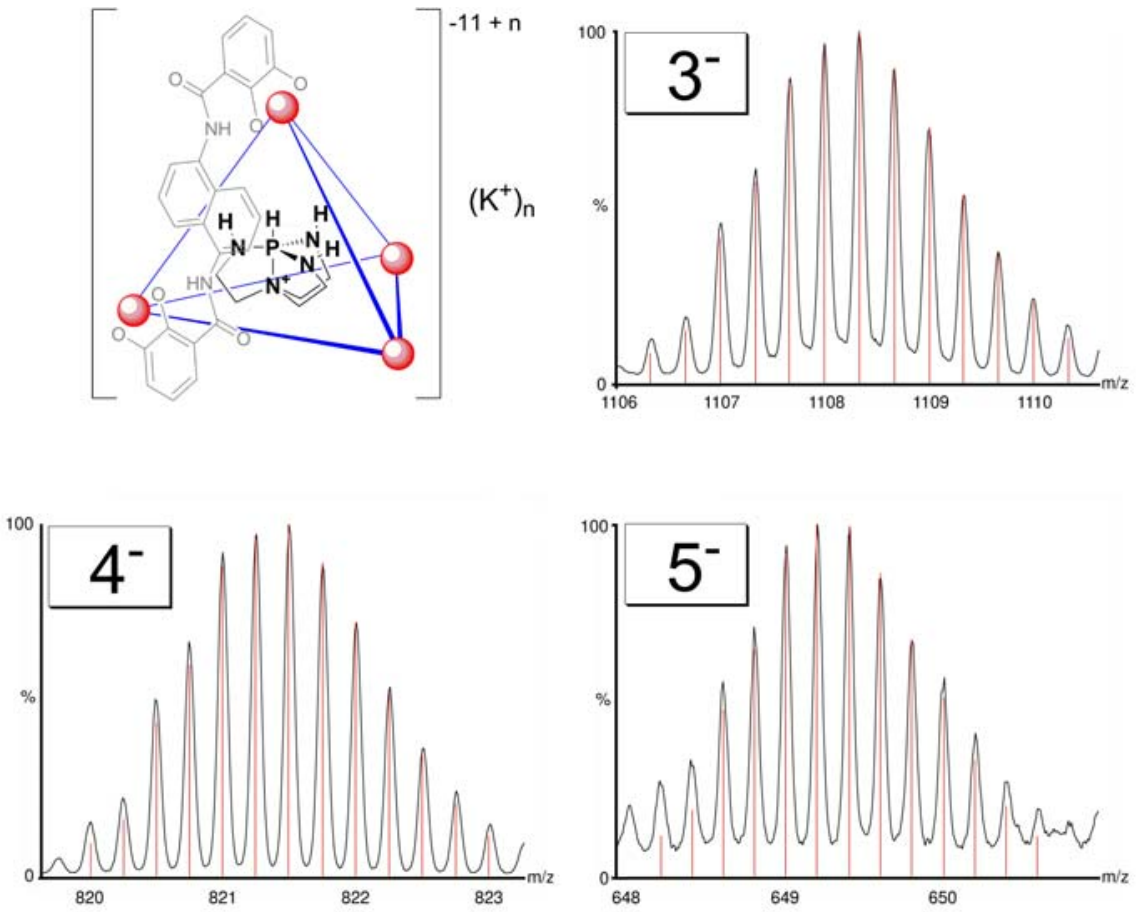

Figure 6 Representative mass spectrometry data for the host guest complex $\mathrm{K}_{8}\left[\mathbf{3 6}-\mathbf{H}^{+} \subset \mathbf{1}\right]^{3-}$, $\mathrm{K}_{7}\left[36-\mathbf{H}^{+} \subset \mathbf{1}\right]^{4-}$, and $\mathrm{K}_{6}\left[36-\mathbf{H}^{+} \subset \mathbf{1}\right]^{5-}$. The calculated spectra are overlaid in red.

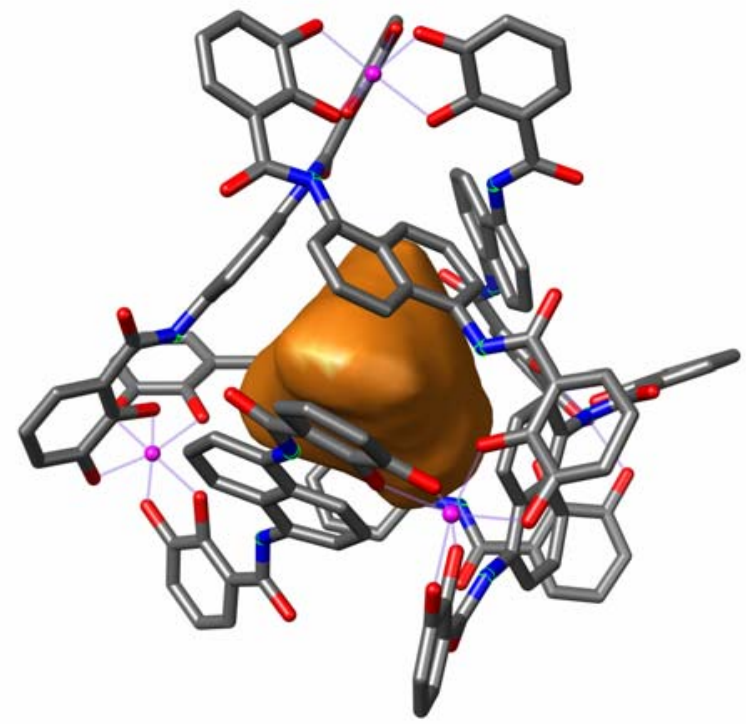

Figure 7. A representation of $\mathbf{1}$ showing the solvent accessible surface of the cavity. 


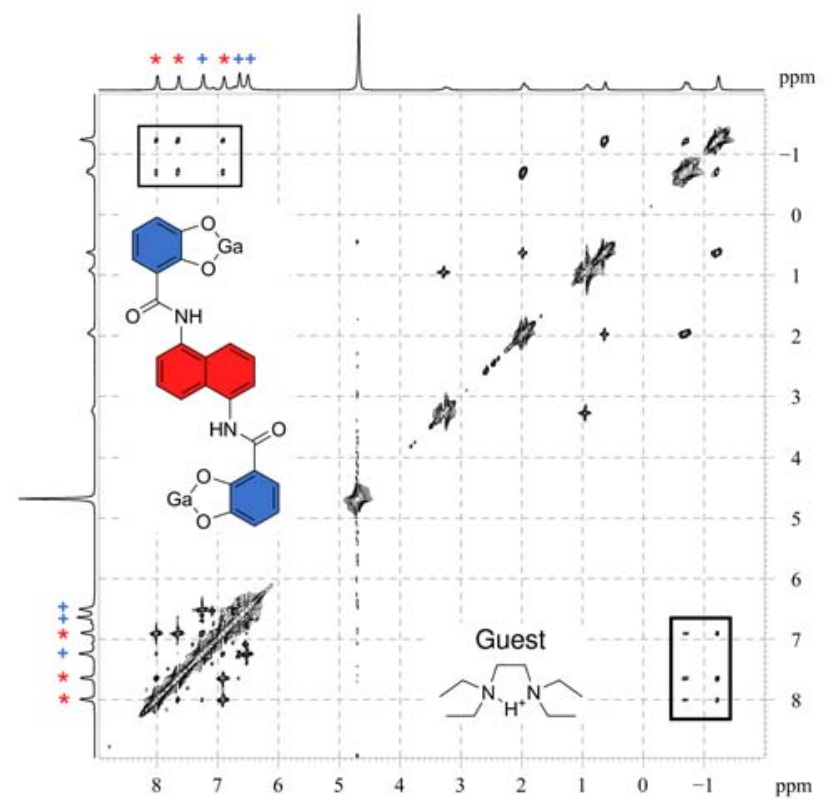

Figure 8. 2D ${ }^{1} \mathrm{H}$ NOESY of $\left[24-\mathbf{H}^{+} \subset \mathbf{1}\right]^{11-}$ in $\mathrm{D}_{2} \mathrm{O}$ with $100 \mathrm{~ms}$ mixing time. Cross peaks between the host and guest are highlighted. The protons of $\mathbf{1}$ are color coded: naphthalene (red $*$ ), catecholate (blue + ).

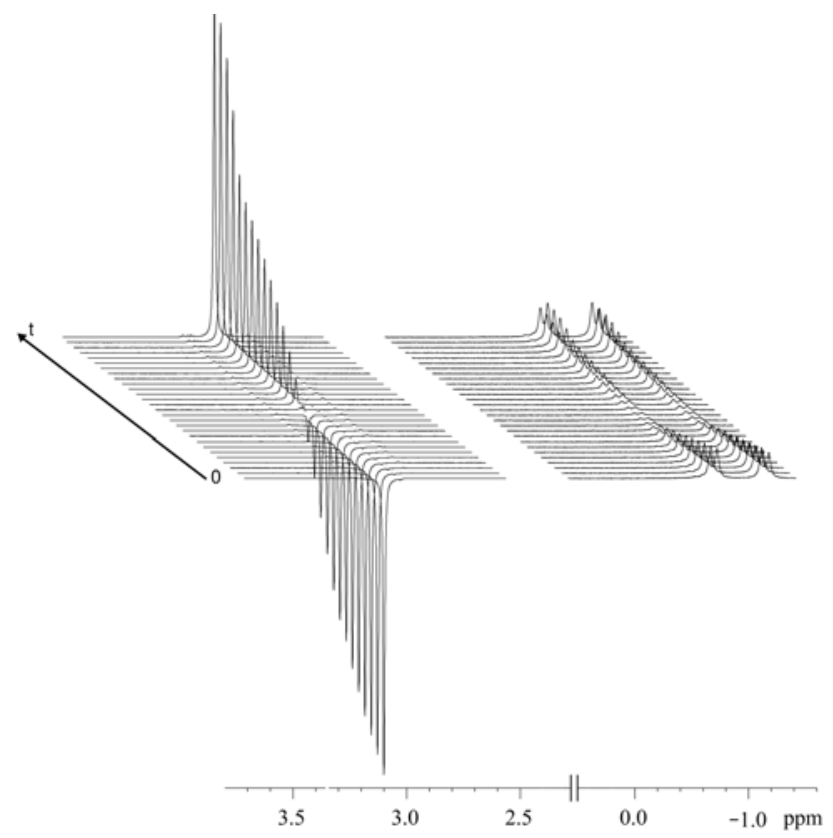

Figure 9. Selective Inversion Recovery experiment for 13. The delay time between the selective inversion centered at the exterior guest (3 ppm) and the acquisition spectrum increases from bottom to top. The spin saturation is transferred to the encapsulated guest through chemical exchange, resulting in a decreased intensity in the guest signals (at $-1 \mathrm{ppm}$ ). 
Table 1. Self-exchange rates and $\mathrm{p} K_{\mathrm{a}}$ 's for selected encapsulated amines.

\begin{tabular}{|l|c|c|l|l|c|}
\hline Amine $^{\mathbf{a}}$ & $\mathbf{p} \boldsymbol{K}_{\mathbf{a}}$ & $\left.\boldsymbol{k}_{\mathbf{2 7 7}} \mathbf{(}^{\mathbf{- 1}}\right)$ & $\mathbf{A m i n e}^{58}$ & $\mathbf{p} \boldsymbol{K}_{\mathbf{a}}$ & $\left.\boldsymbol{k}_{277} \mathbf{s}^{-\mathbf{1}}\right)$ \\
\hline $\mathbf{6}^{57}$ & 10.7 & $46(9)$ & $\mathbf{1 5}^{5}$ & 10.6 & $1.0(5)$ \\
\hline $\mathbf{7}^{59}$ & 10.7 & $0.31(4)$ & $\mathbf{1 7}^{60}$ & 9.1 & $47(9)$ \\
\hline $\mathbf{9}^{61}$ & 10.8 & $17(3)^{\mathrm{b}}$ & $\mathbf{1 8}^{62}$ & 9.8 & $1.1(2)$ \\
\hline $\mathbf{1 0}^{63}$ & 8.5 & $5.3(3)$ & $\mathbf{1 9}^{64}$ & 9.8 & $0.24(3)^{\mathrm{c}}$ \\
\hline $\mathbf{1 2}^{65}$ & 8.3 & $5.4(6)$ & $\mathbf{2 0}^{64}$ & 9.8 & $1.9(3)$ \\
\hline $\mathbf{1 3}^{66}$ & 8.1 & $4.4(6)$ & $\mathbf{2 4}^{67}$ & 10.8 & $0.13(2)^{\mathrm{c}}$ \\
\hline $\mathbf{1 4}^{68}$ & 6.4 & $1.1(1)$ & & & \\
\hline
\end{tabular}

$a$ : The $\mathrm{p} K_{\mathrm{a}}$ references are denoted with superscripts.

$b$ : Measured at $1.1 \mathrm{mM} 1$ and $5.5 \mathrm{mM} 9$ due to low solubility.

c: Exchange rate too slow to measure at $277 \mathrm{~K}$; reported values were measured at $320 \mathrm{~K}$.

$d$ : The exchange rates for substrates $\mathbf{1 1}$ and $\mathbf{2 3}$ were too fast to measure using the SIR method at $277 \mathrm{~K}$.

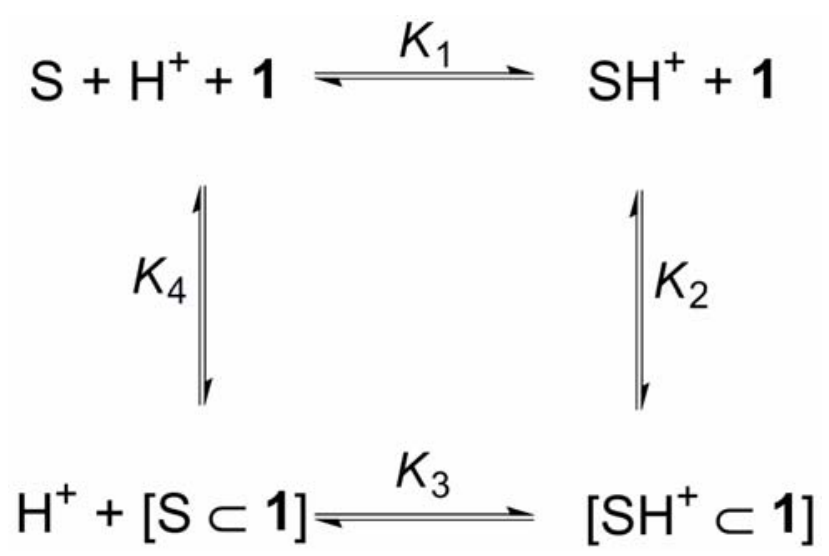

Figure 10. Schematic of the acid-base equilibrium $\left(K_{1}\right)$ and the greatly-favored substrate-host equilibrium $\left(K_{2}\right)$. 
Table 2. Binding constants, energies, and shifts in the effective basicity for encapsulated amines.

\begin{tabular}{|c|c|c|c|c|c|}
\hline Amine & $\mathrm{p} K_{\mathrm{a}}$ & $\begin{array}{r}K_{\text {eff(298) }} \\
\left(\mathbf{M}^{-1}\right)^{\mathrm{a}} \\
\end{array}$ & $\log \left(K_{\text {eff }}\right)$ & $\begin{array}{c}-\Delta G^{\circ} \\
(\mathrm{kcal} / \mathrm{mol})\end{array}$ & $\begin{array}{c}\text { Effective } \\
\text { Basicity }\left(\mathrm{p} K_{\text {eff }}\right)\end{array}$ \\
\hline 6 & 10.7 & 130 & 2.1 & 2.9 & 12.8 \\
\hline 7 & 10.7 & 500 & 2.7 & 3.7 & 13.4 \\
\hline 9 & 10.8 & 2510 & 3.4 & 4.6 & 14.2 \\
\hline 10 & 8.5 & 2080 & 3.3 & 4.5 & 11.8 \\
\hline 12 & 8.3 & 25100 & 4.4 & 6.0 & 12.7 \\
\hline 13 & 8.1 & 31600 & 4.5 & 6.1 & 12.6 \\
\hline 14 & 6.4 & 1590 & 3.2 & 4.4 & 9.6 \\
\hline 15 & 10.6 & 650 & 2.8 & 3.8 & 13.4 \\
\hline 17 & 9.1 & 1260 & 3.1 & 4.2 & 12.2 \\
\hline 18 & 9.8 & 6310 & 3.8 & 5.2 & 13.6 \\
\hline 19 & 9.8 & 6450 & 3.8 & 5.2 & 13.6 \\
\hline 20 & 9.8 & 12600 & 4.1 & 5.6 & 13.9 \\
\hline 24 & 10.8 & 3160 & 3.5 & 4.8 & 14.3 \\
\hline
\end{tabular}

a: Binding constants have an estimated uncertainty of $10 \%$.

$b$ : Binding constants for substrates $\mathbf{1 1}$ and $\mathbf{2 3}$ were not determined due to deprotonation of the methylene hydrogens and substrate decomposition at high $\mathrm{pH}$. 